\title{
Effects of Intermetallic Morphology at the Metallic Particle/ Solder Interface on Mechanical Properties of Sn-Ag-Based Solder Joints
}

\author{
H. RHEE,${ }^{1}$ F. GUO,${ }^{2}$ J.G. LEE,${ }^{1}$ K.C. CHEN,${ }^{3}$ and K.N. SUBRAMANIAN ${ }^{1,4}$ \\ 1.-Department of Chemical Engineering and Materials Science, Michigan State University, East \\ Lansing, MI 48824. 2.-Department of Electrical and Computer Engineering, Michigan State Uni- \\ versity. 3.-Materials Engineering Department, California Polytechnic State University, San Luis \\ Obispo, CA 93407. 4.—subraman@egr.msu.edu
}

Mechanical incorporation of metallic particles in the Sn-Ag-based solder resulted in various intermetallic compound (IMC) morphologies around these particles during reflow. Unlike with the Ni particles, the IMCs formed around $\mathrm{Cu}$ and $\mathrm{Ag}$ particles are relatively insensitive to reflow profiles employed. The IMC formed around the Ni particles ranges from "sunflower" morphology to "blocky" morphology with increasing time and temperature above liquidus during the heating part of the reflow profile. Mechanical properties, such as simple shear strength and creep behavior, of these composite solders were affected by the IMC morphologies in the composite solders investigated. Sunflower-shaped IMC formed around an Ni particles resulted in higher simple shear strength and better creep properties.

Key words: Composite lead-free solder joints, mechanical behavior, IMC morphology

\section{INTRODUCTION}

Among potential candidates to replace lead-bearing solders, Sn-based solders have gained significant attention as a possible substitute because of their comparable performances. Severe operational environments, such as automotive under-the-hood applications and the miniaturization trend in electronic devices, require that solder joints not only be a reliable electrical interconnection but also have structural integrity. Several approaches have been reported to improve Sn-based solder properties, such as mechanical strength, creep resistance, thermomechanical fatigue resistance, solder joint reliability, etc. ${ }^{1-10}$ The composite approach is one of the potential methodologies to improve the properties of lead-free solder joints.

The mechanical behavior of the composite solder joint depends on the reinforcing phases present. Such reinforcements can be introduced by in-situ methods or by mechanical means. Compatible inter- metallic compounds (IMCs) can be produced by converting metallic particles during reflow. Mechanical properties of the composite solder joint will also depend on the type of IMC and its morphological features.

Studies dealing with the formation of an IMC around intentionally incorporated $\mathrm{Cu}, \mathrm{Ag}$, and $\mathrm{Ni}$ particles within the eutectic Sn-Ag matrix have shown that various morphological features can result as a consequence of the reflow condition. ${ }^{11}$ For example, the IMCs formed around Ag particles neither change significantly in volume nor change their morphology under different reflow conditions. Copper particles in reinforced-composite solders show significant growth of IMC layers that can completely consume the $\mathrm{Cu}$ particles. However, this composite also does not exhibit significant changes in IMC morphology as a consequence of reflow profiles. The IMC formed around the Ni particle in the Sn-Agbased solder matrix exhibits significantly different morphological features based on reflow profiles and the presence of $\mathrm{Cu}$. Because these features may impact the mechanical behavior of actual solder joints, 
the current study evaluates the roles of morphological features of the reinforcing phases on the mechanical properties of the Sn-Ag-based composite solder joints.

\section{EXPERIMENTAL PROCEDURES}

\section{Preparation of Composite Solder Joints}

Three different types of composite solder joints based on the eutectic Sn-3.5Ag composition were used in the present study. The composite solder materials were prepared by mechanically mixing (1) $\sim 10-\mu \mathrm{m}$ $\mathrm{Cu},(2) \sim 1-\mu \mathrm{m} \mathrm{Ag}$, and (3) $\sim 5-\mu \mathrm{m}$ Ni particles into eutectic $\mathrm{Sn}-\mathrm{Ag}$ solder paste for about $20 \mathrm{~min}$ to promote uniform particle distribution. These composite solder materials contained approximately 20 vol.\% reinforcements. The details of the preparation of these composite solders can be found elsewhere. ${ }^{8}$ Single shear-lap joints were produced by soldering two dogbone-shaped $\mathrm{Cu}$ strips using one of the composite solder pastes. The solder joints were made by placing the entire assembly in a fixture and melting the solder on a preheated hot plate until it reached a peak temperature of $280^{\circ} \mathrm{C}$. These joints had approximately a $1 \mathrm{~mm} \times 1 \mathrm{~mm}$ joint area and a thickness of about $100 \mu \mathrm{m}$. Details of the fabrication of the solder joints can be found elsewhere. ${ }^{12}$

Solder reflows were carried out with a heating rate of $5^{\circ} \mathrm{C} / \mathrm{sec}$ to reach $280^{\circ} \mathrm{C}$ and cooling down on an aluminum chill block. ${ }^{11}$ Such a reflow profile resulted in a sunflower morphology of the IMC around the Ni particles. Repeating this reflow four times converted this IMC morphology into a blocky shape.

After making the composite solder joints, both sides of the joint were roughly polished to remove extruded solder from the edges. This was followed by fine polishing of one side of the joint to observe the microstructure prior to and after mechanical testing. The morphology of the IMC phases at the particle/solder interface within the solder joint matrix was characterized using scanning electron microscopy (SEM).

\section{Shear Test}

The shear tests were carried out on a Rheometric Solids Analyzer (RSA-III) made by Rheometric Scientific, Inc. (Piscataway, NJ) at the various simple shear rates of $0.001 / \mathrm{s}, 0.01 / \mathrm{s}$, and $0.1 / \mathrm{s}$ at different temperatures $\left(25^{\circ} \mathrm{C}, 85^{\circ} \mathrm{C}\right.$, and $\left.150^{\circ} \mathrm{C}\right)$. Details regarding the performance and advantages of this apparatus can be found elsewhere. ${ }^{12}$

The simple shear value for each tested solder joint was calculated by dividing actual displacement imposed on the joint by actual joint thickness. This parameter is too large to be termed as "shear strain," so "simple shear" would be a more appropriate term. ${ }^{12,13}$ Likewise, the term "simple shear rate" is used instead of the term "shear strain rate." The simple shear rates imposed were obtained by choosing appropriate displacement rates depending on actual solder joint thickness. The detailed explanation of the nomenclature and calculation for simple shear and simple shear rate can be found elsewhere. ${ }^{12,13}$ The actual shear-stress values were obtained by dividing the load by the solder joint area after subtracting the pore area observed in the fracture surfaces. Because the RSA-III used in this study is an extremely soft machine and controls displacement rather than strain, the reported simple-shear values are already corrected for the compliance of the machine. The machine compliance value was obtained by testing a copper specimen with geometry similar to the solder joint specimen. This specimen was made with hard epoxy, instead of the solder, to hold the two copper strips together. After obtaining the machine compliance value, actual displacements imposed on the solder joint were obtained by subtracting the deformation of the machine and the copper strips from the imposed displacement.

After the completion of the shear test on a given specimen, deformation structures were observed from the fine-polished side surfaces of the solder joints using SEM.

\section{Creep Test}

Creep testing was carried out on these solder joints, marked with a laser pattern or a scratch, ${ }^{14}$ using dead-weight loading on a miniature creeptesting frame fixed on an optical microscope. The deformation of the polished side of the solder joint was monitored using a Kodak (Rochester, NY) chargecouple device camera connected to a microscope and a computer. The creep data were obtained by mapping the time-sequence images of the distorted laser-ablation patterns or a scratch mark at set time intervals. Creep tests were conducted at $25^{\circ} \mathrm{C}$ and $85^{\circ} \mathrm{C}$ on the solder joints representing homologous temperatures $\mathrm{T} / \mathrm{T}_{\text {melt }\left({ }^{\circ} \mathrm{K}\right)}=0.6$ and 0.72 , respectively. For elevated temperature tests, the solder joint was heated by conduction with a heating pad affixed to the $\mathrm{Cu}$ strip. The testing temperature was monitored by a thermocouple in close contact with the solder joint. The details of this creep-testing process and data-process technique is documented in previously published papers. ${ }^{9,14-16}$

\section{RESULTS AND DISCUSSION}

\section{Microstructures of Composite Solder Joints}

Typical microstructures of as-fabricated $\mathrm{Cu}-, \mathrm{Ag}$-, and Ni-composite solder joints based on the eutectic Sn-Ag solder are shown in Fig. 1 along with a Nicomposite solder joint that had been reflowed four times. The $\mathrm{Cu}$-composite solder joint has a scallopshaped IMC layer, whereas the Ag-composite solder joint has a very thin layer of IMC around the metallic particles. The effect of multiple reflow on the growth of the IMC formed around Ni particle reinforcements can also be seen. The blocky morphology develops after the fourth reflow (Fig. 1d), whereas the initial morphology of the IMC around the $\mathrm{Ni}$ particle is the sunflower shape (Fig. 1c). A detailed 

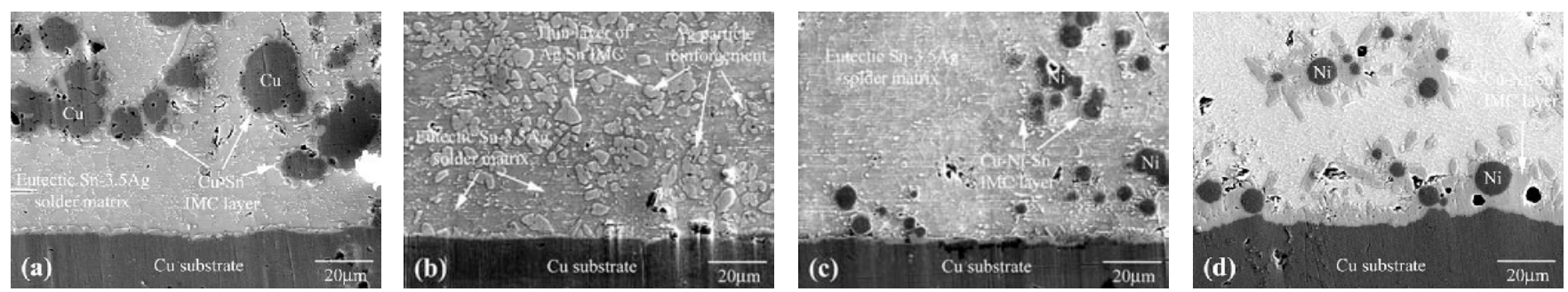

Fig.1. Microstructures of composite solder joints based on eutectic Sn-3.5Ag solder: as-fabricated conditions of (a) Cu-composite, (b) Ag-composite, (c) Ni-composite solder joints, and (d) four times reflowed Ni-composite solder joint.

explanation of these features can be found elsewhere. ${ }^{11,17}$

\section{Shear Test}

The shear-stress versus simple-shear curves for the various composite solder joints tested at a simple shear rate of $0.001 / \mathrm{s}$ at each of the three temperatures are shown in Fig. 2. Shear-stress versus simple-shear curves as a function of strain rate at a testing temperature of $150^{\circ} \mathrm{C}$ are depicted in Fig. 3 . These plots are typical of those for the various tested conditions of simple shear rates of $0.001 / \mathrm{s}$, $0.01 / \mathrm{s}$, and $0.1 / \mathrm{s}$ at different testing temperatures of $25^{\circ} \mathrm{C}, 85^{\circ} \mathrm{C}$, and $150^{\circ} \mathrm{C}$. The maximum shear stress and the flow stress level of those composite solder joints depend strongly on both testing temperature and simple shear rate. Plots given in Fig. 4 show the maximum shear stress as a function of simple shear rate at different testing temperatures. The maximum shear stress increases significantly with increasing simple shear rate at all testing temperature ranges for all composite solder joints. Also, one can clearly observe that the maximum shear stress is strongly affected by testing temperatures. The maximum shear stress decreases with increasing testing temperature at all simple-shear rate levels for all composite solder joints.

Figure 5 provides an overall comparison of the maximum shear stress of the composite solder joints as a function of temperature at a fixed, simple-shear rate along with that of the eutectic Sn-Ag solder joint. One can clearly observe that the as-fabricated, Ni-composite solder joint containing sunflower morphology exhibited the highest maximum shear-stress levels for all test conditions followed by the Cu-composite solder joint containing a scallop-shaped IMC
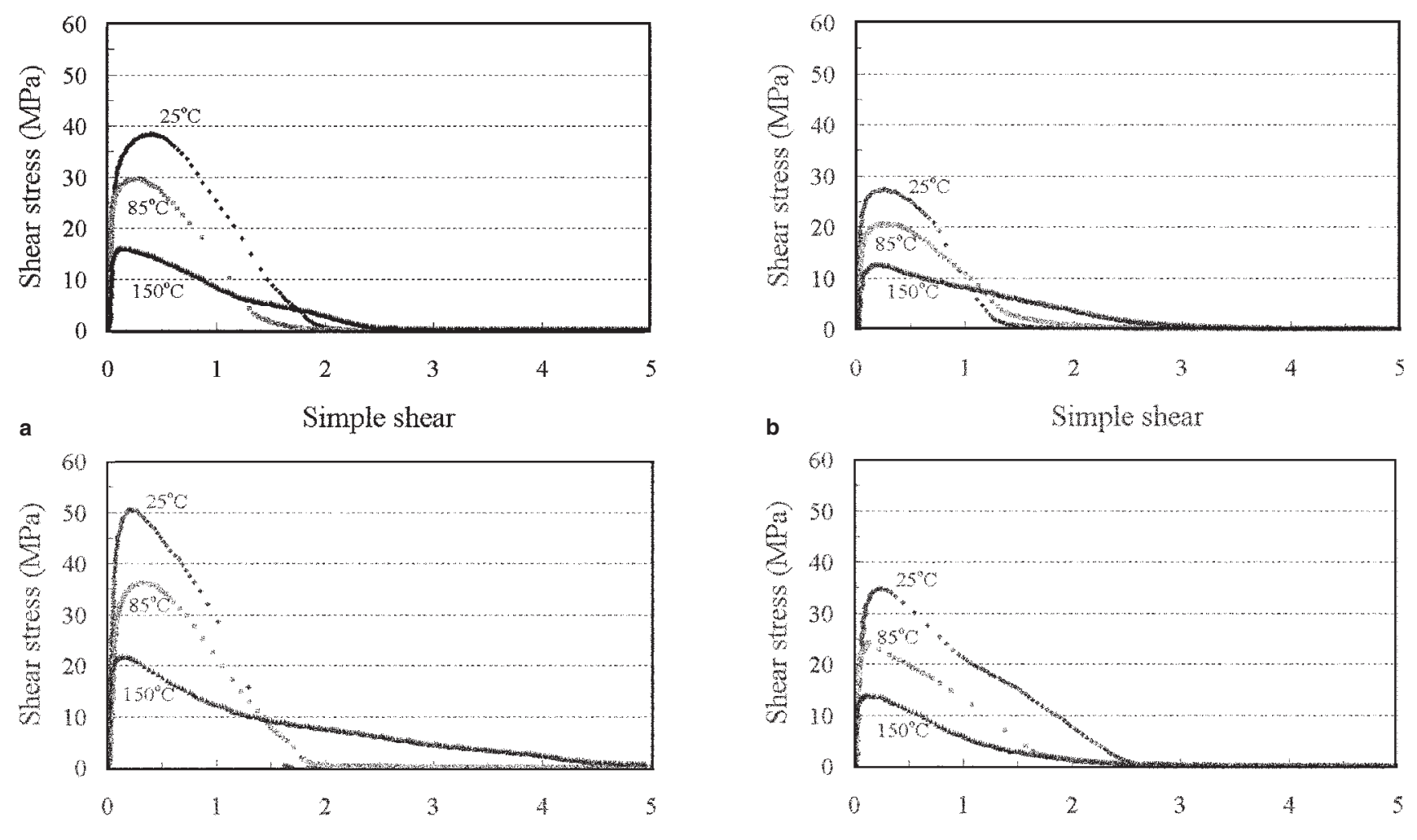

c

Simple shear

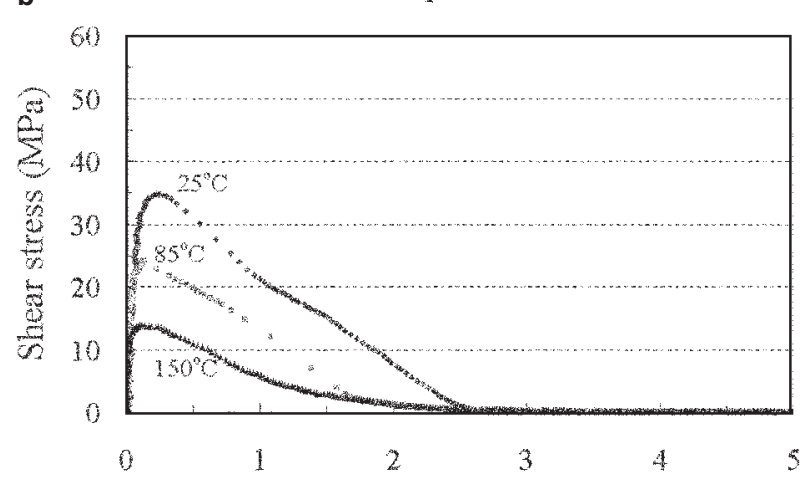

d

Simple shear

Fig. 2. Shear stress versus simple shear plots for various composite solder joints at simple shear-rate of $0.001 / \mathrm{s}$ at different testing temperatures: as-fabricated conditions of (a) Cu-composite, (b) Ag-composite, (c) Ni-composite solder joints, and (d) four times reflowed Ni-composite solder joints. 


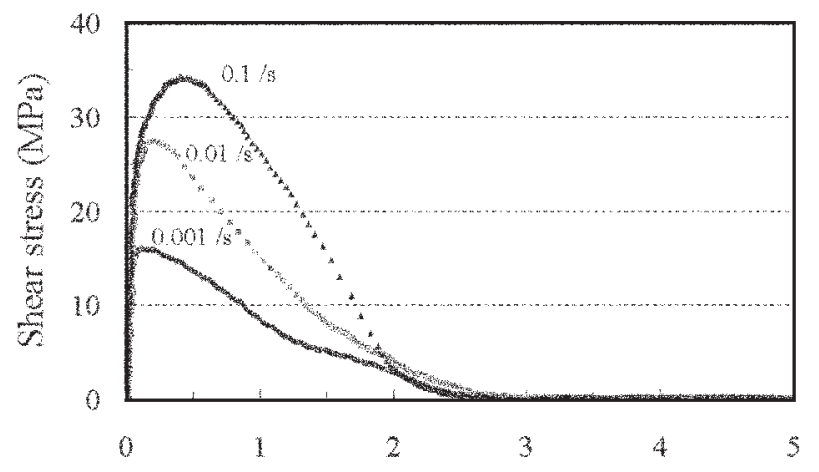

a

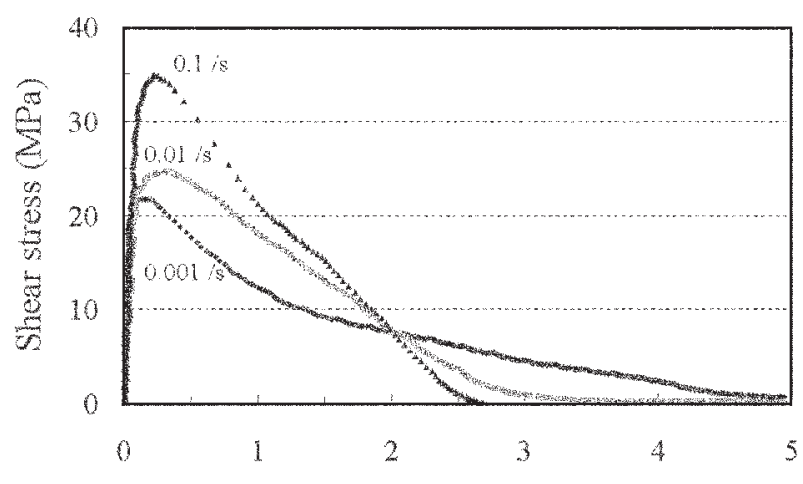

c
Simple shear

Simple shear
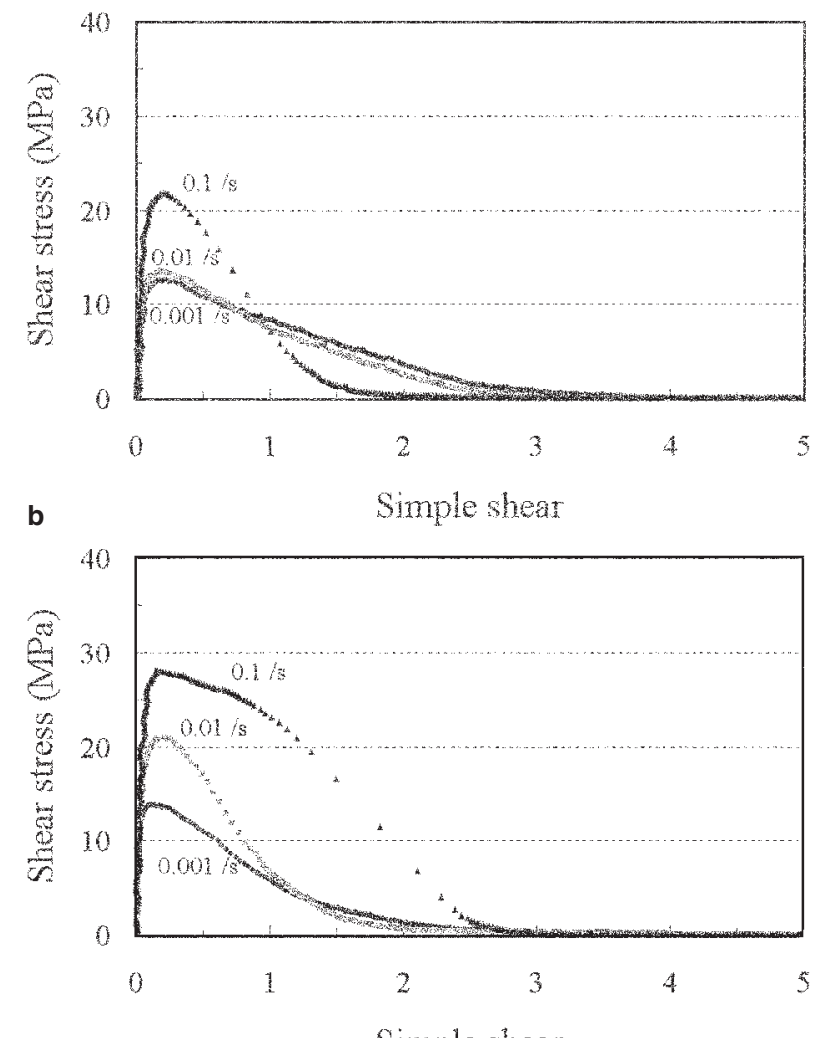

d

Simple shear

Fig. 3. Shear stress versus simple shear plots for various composite solder joints at $150^{\circ} \mathrm{C}$ at different simple shear-rates: as-fabricated conditions of (a) Cu-composite, (b) Ag-composite, (c) Ni-composite solder joints, and (d) four times reflowed Ni-composite solder joints.
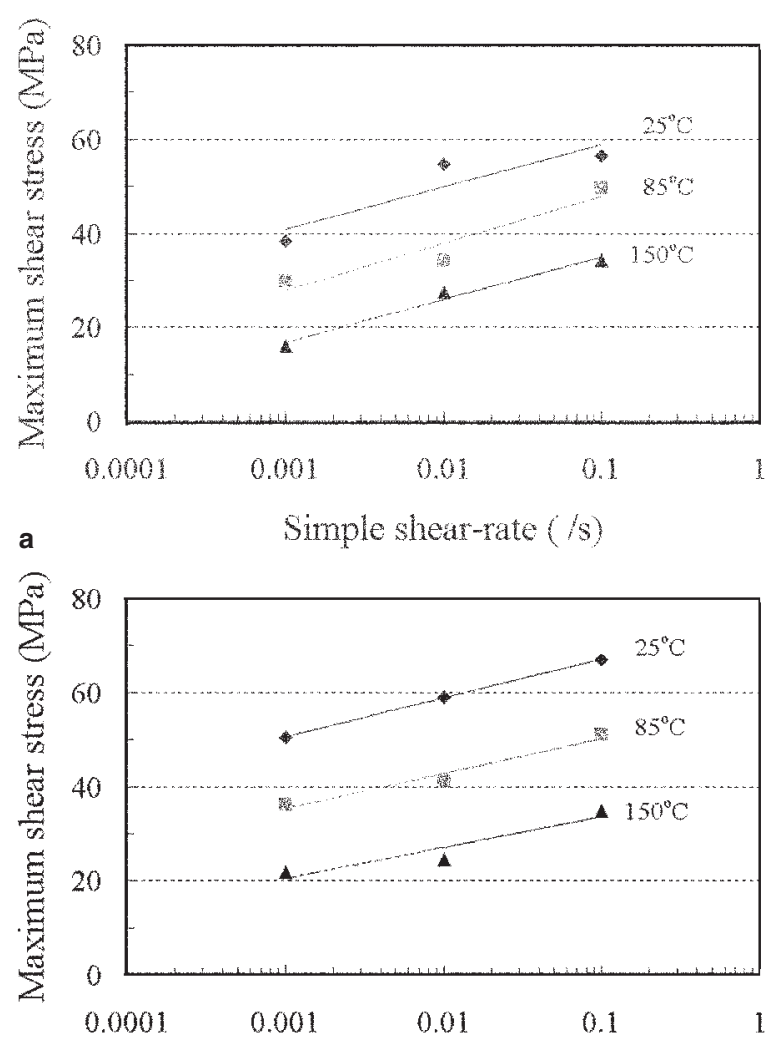

c

C

Simple shear-rate $(/ \mathrm{s})$
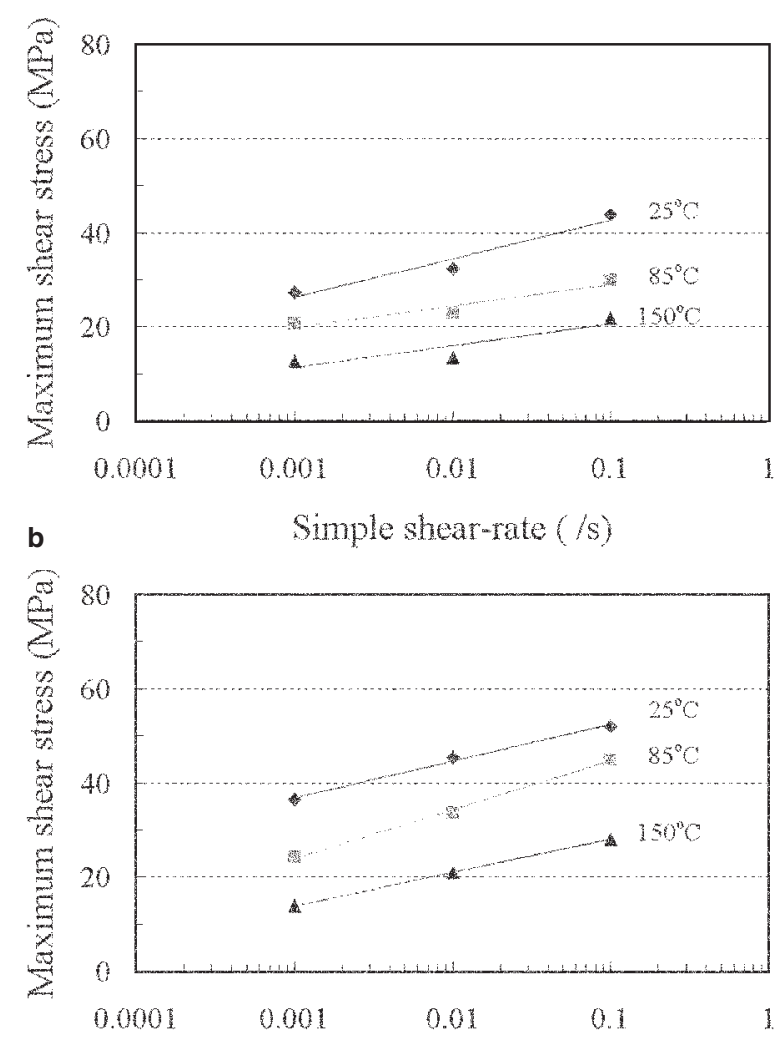

d Simple shear-rate $(/ \mathrm{s})$

Fig. 4. Maximum shear stress as a function of simple shear-rate at different temperatures: as-fabricated conditions of (a) Cu-composite, (b) Agcomposite, (c) Ni-composite solder joints, and (d) four times reflowed Ni-composite solder joints. 


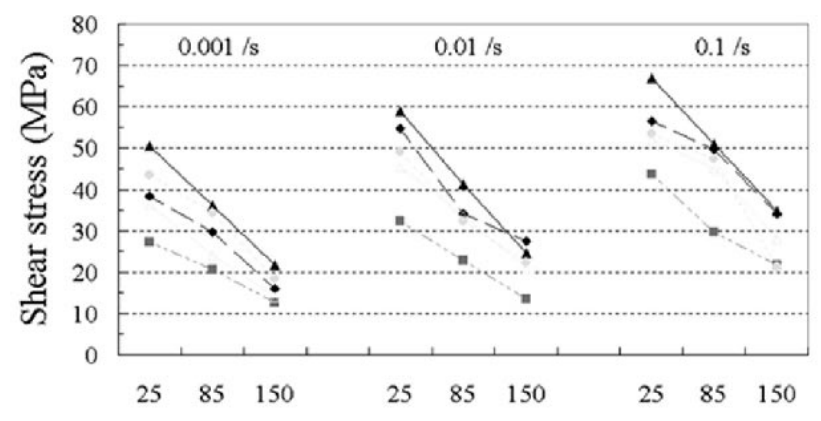

Temperature $\left({ }^{\circ} \mathrm{C}\right)$

$\rightarrow$ Cu-composite $\cdots-$ Ag-composite $\leftarrow$ Ni.composite Eutectic Sn-3.5Ag Reflowed Ni-composite

Fig. 5. Comparison of shear strength of the $\mathrm{Cu}, \mathrm{Ag}$, and Ni composite solder joints at various temperatures along with eutectic $\mathrm{Sn}-3.5 \mathrm{Ag}$ solder joint. ${ }^{12}$

layer around the $\mathrm{Cu}$ reinforcement. Both composite solder joints exhibited better shear strength compared to the eutectic Sn-Ag solder joint. However, the Ag-composite solder joint, which contains a very thin IMC layer, exhibited the worst shear strength at all the conditions employed. The maximum shear-stress level of the Ag-composite solder joint is even lower than that of the eutectic $\mathrm{Sn}-\mathrm{Ag}$ solder joint. The Nicomposite solder joint, containing blocky IMC morphology that resulted after four reflows, exhibited much lower shear strength than that containing the sunflower-shaped IMC.

The microstructures of the solder-joint side surfaces after shear testing at a simple shear rate of $0.01 / \mathrm{s}$ at $25^{\circ} \mathrm{C}$ and $150^{\circ} \mathrm{C}$ are shown in Fig. 6. The deformation at $25^{\circ} \mathrm{C}$ is dominated by the shearbanding mode, whereas at $150^{\circ} \mathrm{C}$, it is by a grainboundary deformation. The effect of reinforcing particles and IMC morphology formed around those metallic particles on the deformation features can also be seen. The shear bands do not propagate through the reinforcing particles but flow around these obstacles, suggesting that deformation is retarded by these particles, causing composite solders to have much higher shear strength than the base solder material. However, the IMC formed around $\mathrm{Ag}$ is very thin, so that this effect is not sufficient to retard the propagation of shear deformation.

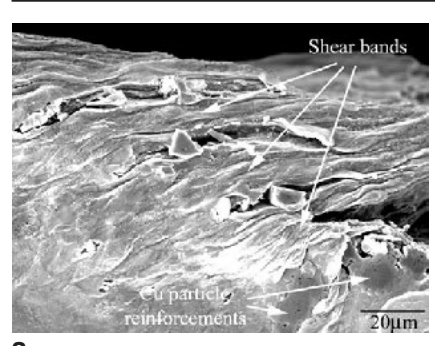

a

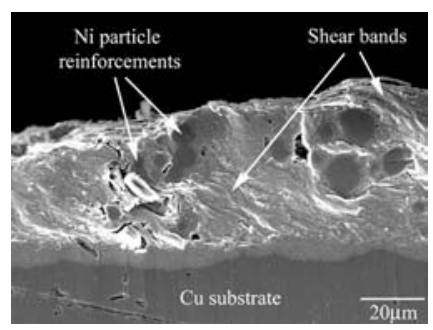

e

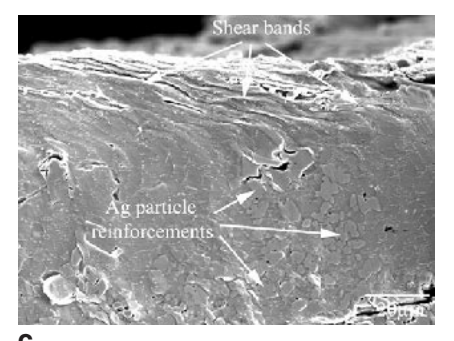

c

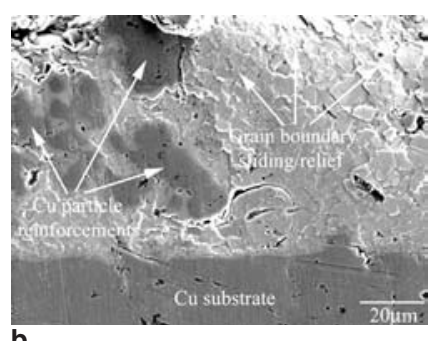

b

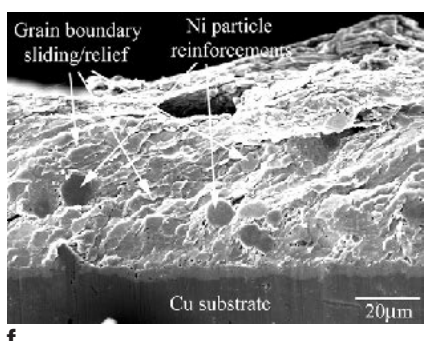

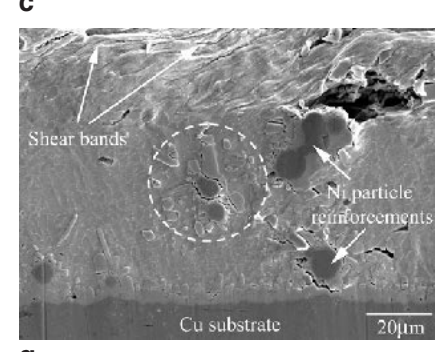

g

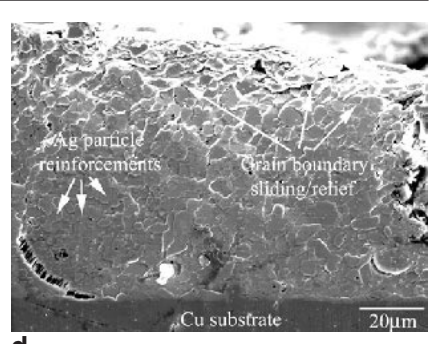

d

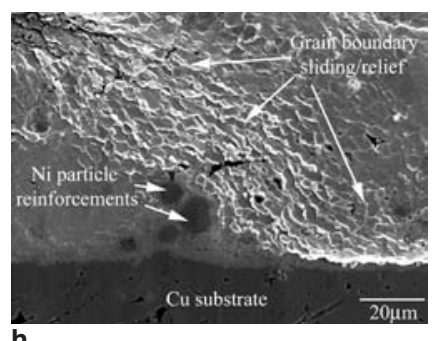

Fig. 6. Microstructures of the composite solder joint side surfaces after shear test with a simple shear-rate of $0.01 / \mathrm{s}$ at various temperatures: (a) Cu composite at $25^{\circ} \mathrm{C}$, (b) Cu composite at $150^{\circ} \mathrm{C}$, (c) Ag composite at $25^{\circ} \mathrm{C}$, (d) Ag composite at $150^{\circ} \mathrm{C}$, (e) Ni composite at $25^{\circ} \mathrm{C}$, (f) $\mathrm{Ni} \mathrm{com}-$ posite at $150^{\circ} \mathrm{C}$, (g) four times reflowed $\mathrm{Ni}$ composite at $25^{\circ} \mathrm{C}$, and (h) four times reflowed Ni composite at $150^{\circ} \mathrm{C}$.

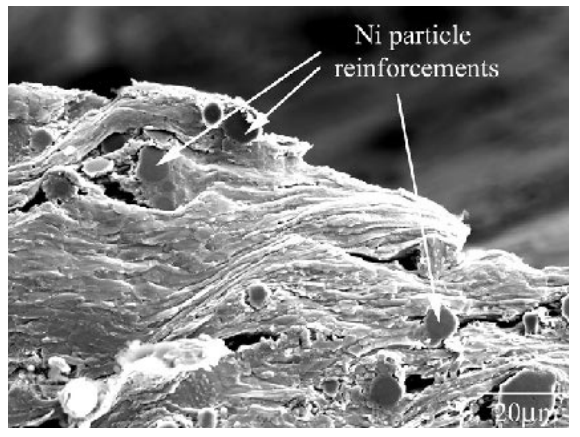

a

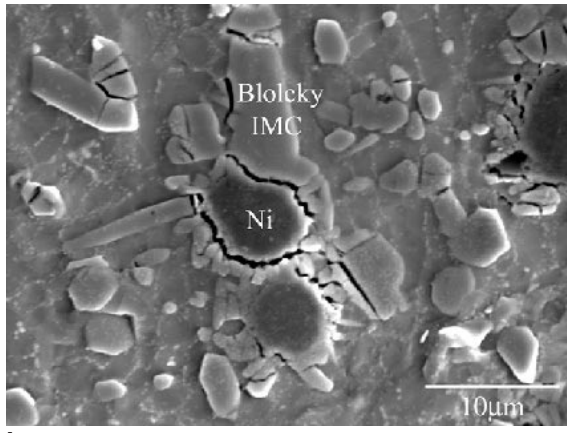

b

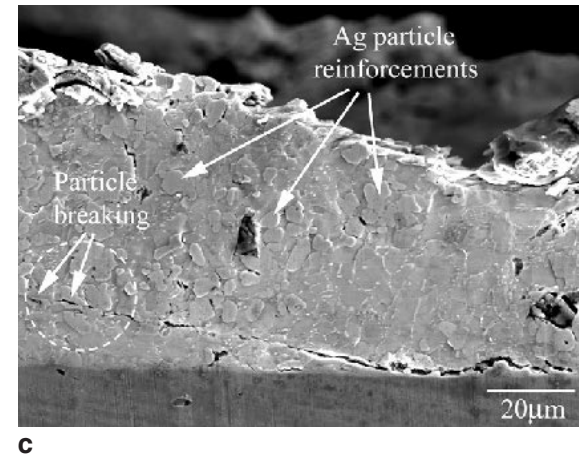

c

Fig. 7. Features of the IMCs formed around reinforcing particles within the composite solder joints: (a) Ni composite solder joint with sunflower IMC morphology (specimen deformed simple shear-rate of $0.1 / \mathrm{s}$ at $85^{\circ} \mathrm{C}$ ), (b) Ni composite solder joint with blocky IMC morphology (enlarged view of Fig. $6(\mathrm{~g})$; specimen deformed simple shear rate of $0.01 / \mathrm{s}$ at $25^{\circ} \mathrm{C}$ ), and (c) Ag composite solder joint (specimen deformed simple shearrate of $0.001 / \mathrm{s}$ at $\left.25^{\circ} \mathrm{C}\right)$. 
Figure 7 shows Ni- and Ag-composite solder deformation structures. These images indicate the roles of the IMC around reinforcing particles. This shows that the IMC, formed around all reinforcing particles, can be tortuous and retard the fracture path except those formed around the Ag particle.

Figure 8 is a schematic showing the fracture path in these composite solders. The fracture path in the $\mathrm{Cu}$ composite solder follows the interface between the $\mathrm{Cu}_{6} \mathrm{Sn}_{5} \mathrm{IMC}$ and the solder. In the Ag-composite solder, the fracture path not only follows the interface of the thin IMC layer and solder, but also cuts through the particles. In the Ni composite with sunflower IMC morphology, the fracture encounters a tortuous path. In the Ni composite with blocky IMC morphology, the fracture cuts through the $\mathrm{Cu}-\mathrm{Ni}-\mathrm{Sn}$ IMC layer and follows the interface between $\mathrm{Ni}$ and the IMC. This path will be less torturous compared to the one encountered with the sunflower IMC morphology. The scallop-shaped IMC/solder inter- face in the Cu-reinforced composite solder provides a situation that will be intermediate between the preceding two extremes.

The creep parameters can be extracted from the shear tests because homologous temperatures of these composite solder joints are greater than $0.5 \mathrm{~T}_{\mathrm{m}}$ even at room temperature. The power-law creep equation ${ }^{18}$ gives good fits for the simple shear rate versus maximum shear stress relationship from these composite solder joints' shear data at $25^{\circ} \mathrm{C}$, $85^{\circ} \mathrm{C}$, and $150^{\circ} \mathrm{C}$. The creep parameters from the shear tests were depicted in Figs. 9 (stress exponent) and 10 (creep activation energy), respectively. Again, the Ni-composite solder joint containing the sunflower-shaped IMC exhibited the highest average stress-exponent value of $\sim 12.9$, and the stressexponent value at each testing temperature is much higher than that of the eutectic Sn-Ag solder joint obtained under similar test conditions. ${ }^{12}$ These results are the probable causes of getting higher creep
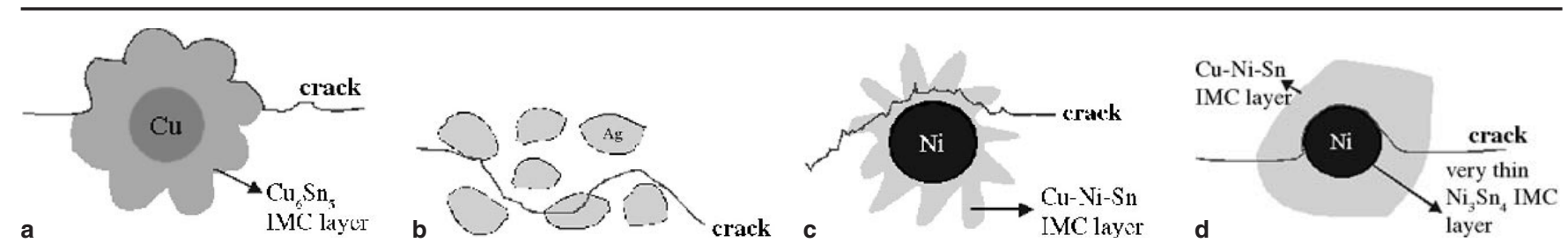

Fig. 8. Schematics of fracture paths in various composite solder joints: (a) Cu composite solder, (b) Ag composite solder, (c) Ni composite solder with sunflower IMC morphology, and (d) Ni composite with blocky IMC morphology.

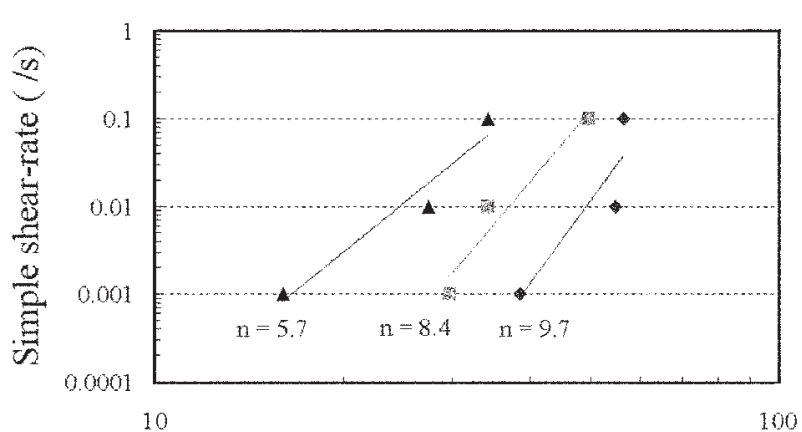

Maximum shear stress (MPa)

a

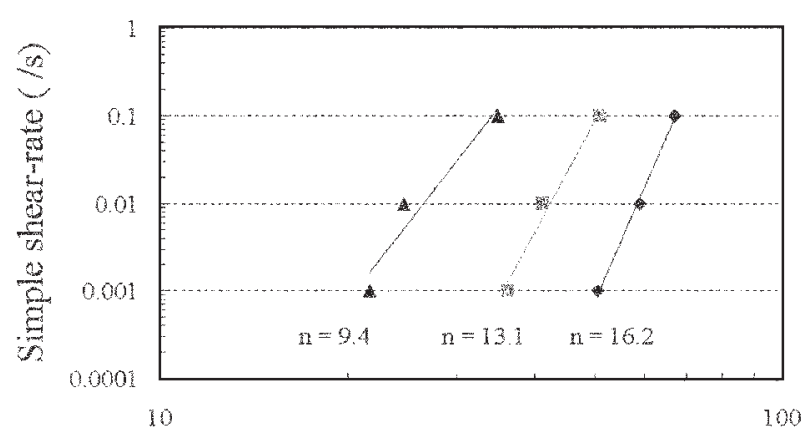

Maximum shear stress (MPa)

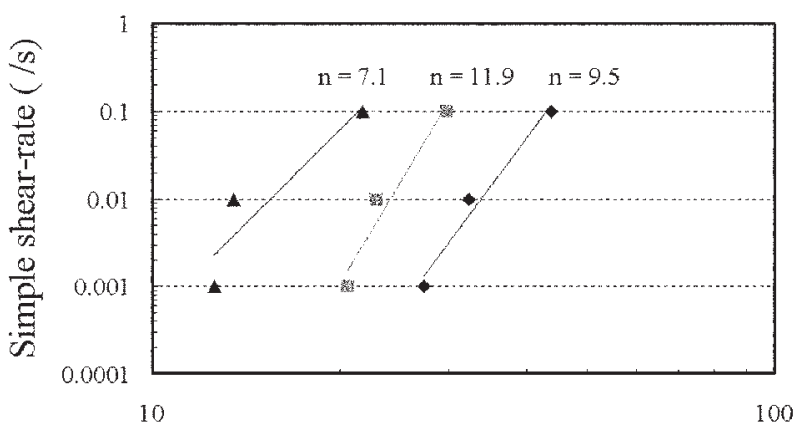

Maximum shear stress $(\mathrm{MPa})$

b

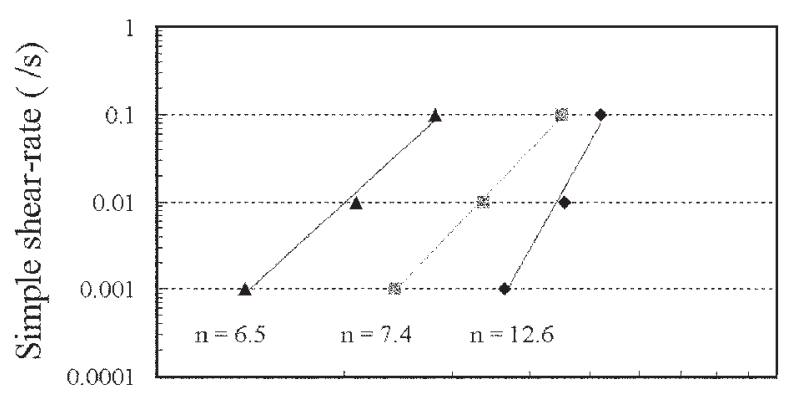

10

Maximum shear stress (MPa)

c $\quad 25 \mathrm{C} 88 \mathrm{C} \$ 150 \mathrm{C} \quad+25 \mathrm{C}$ a $85 \mathrm{C} \triangle 150 \mathrm{C}$

Fig. 9. Relationship between simple shear-rate and maximum shear stress: as-fabricated conditions of (a) Cu-composite, (b) Ag-composite, (c) $\mathrm{Ni}$-composite solder joints, and (d) four times reflowed Ni-composite solder joints. 

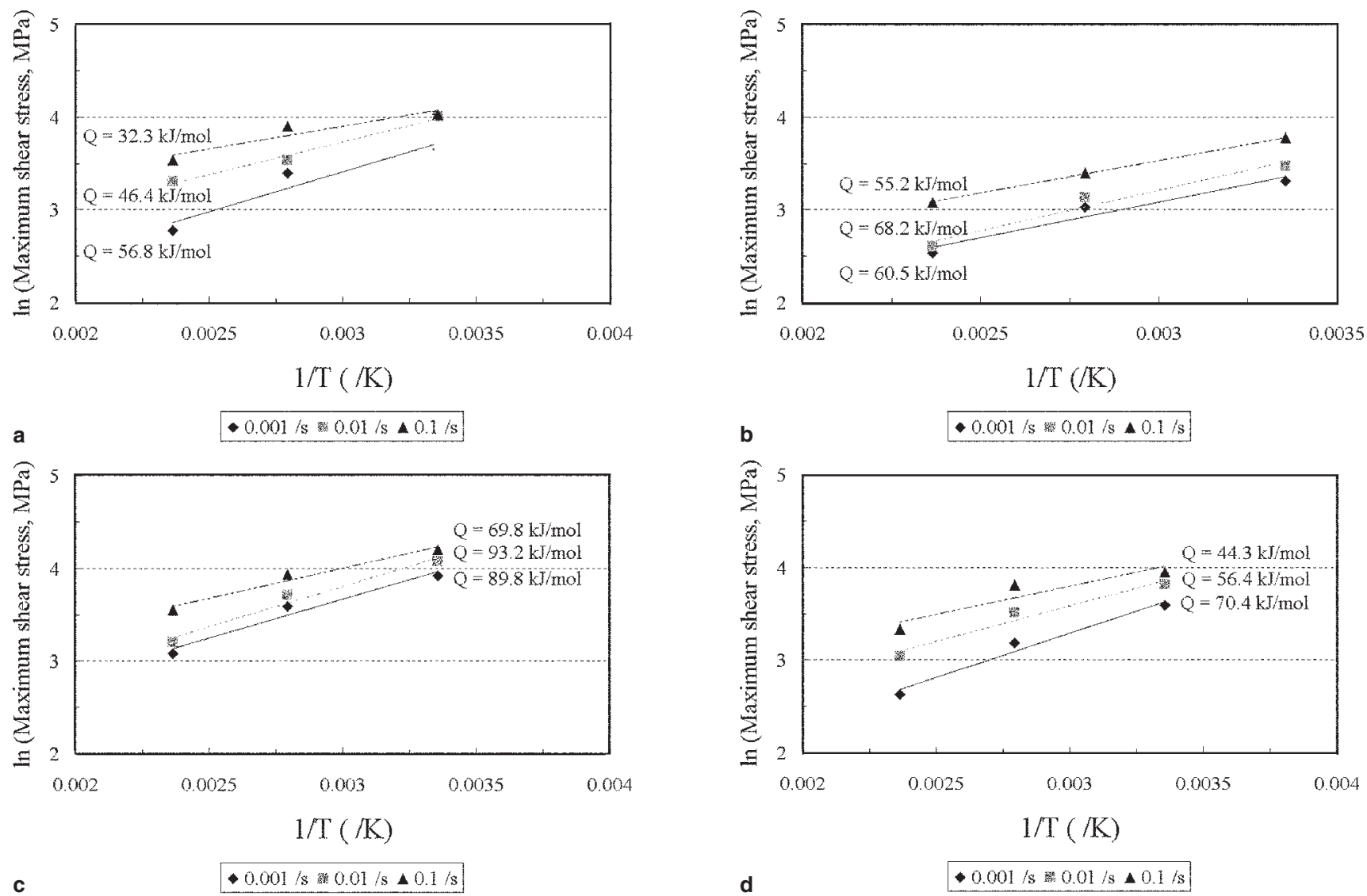

Fig. 10. Relationship between shear stress and testing temperature at different simple shear-rates: as-fabricated conditions of (a) Cu-composite, (b) Ag-composite, (c) Ni-composite solder joints, and (d) four times reflowed Ni-composite solder joints.

activation energy for $\mathrm{Ni}$-composite solder joints, as provided in Fig. 10.

\section{Creep Test}

Steady-state creep rates of composite solder joints with the Ni-composite solder having a blocky IMC morphology were measured under a nominal stress at $17 \mathrm{MPa}$ using a miniature creep-testing frame. These tests were conducted at $25^{\circ} \mathrm{C}$ and $85^{\circ} \mathrm{C}$ on the Ni-composite solder joint with the blocky-shaped IMC. These data are plotted as a function of testing temperature in Fig. 11 and compared in the same figure with previously reported steady-state rates for the Ni-composite solder joints with sunflower IMC morphology, $\mathrm{Cu}$-reinforced composite, Ag-reinforced composite, eutectic $\mathrm{Sn}-3.5 \mathrm{Ag}$, and $\mathrm{Sn}-4 \mathrm{Ag}-0.5 \mathrm{Cu}$ solder joints tested under similar experimental conditions. ${ }^{9,15}$ The previous creep tests have been carried out at $25^{\circ} \mathrm{C}, 65^{\circ} \mathrm{C}$, and $105^{\circ} \mathrm{C}$. It is clearly shown in this superimposed figure that the Ni-composite solder joints with sunflower IMC morphology exhibited the lowest steady-state creep rate. At both room temperature and $85^{\circ} \mathrm{C}$, the Ni-composite solder joints containing blocky reinforcements had a steady-state creep rate higher than the $\mathrm{Ni}$-composite solder joint with sunflower IMC morphology as well as the composite solder joints made with $\mathrm{Cu}$ reinforcements. However, these composite solder joints showed better creep resistance than the Ag composite, eutectic

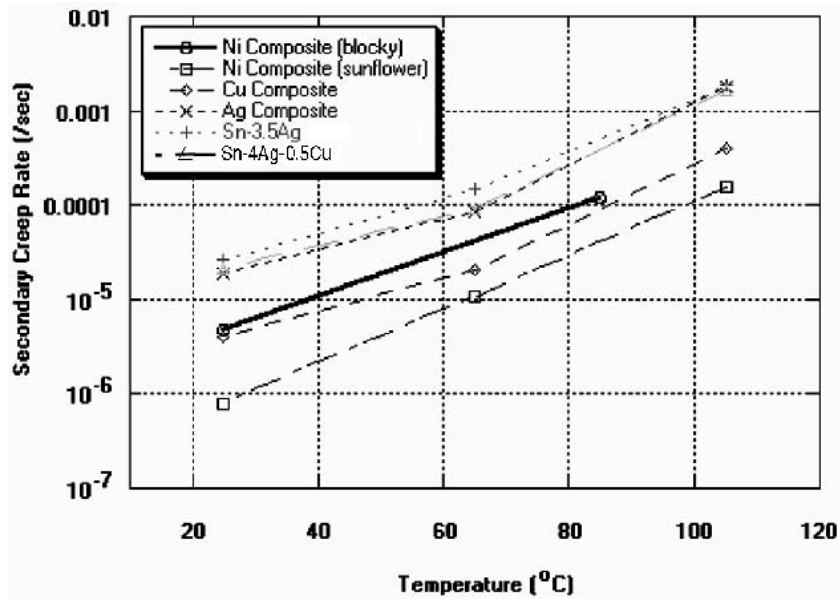

Fig. 11. Steady-state creep rates of composite solder joints. Note: Data for Ni composite (blocky) obtained in current study. Rest from previously published data. ${ }^{9}$

$\mathrm{Sn}-3.5 \mathrm{Ag}$, and the ternary $\mathrm{Sn}-4 \mathrm{Ag}-0.5 \mathrm{Cu}$ solder joints. It is reasonable to relate the IMC morphology of the reinforcement particles to the ranking of creep resistance of these composite solder joints. Sunflower-shaped IMC reinforcements improve the creep resistance of the solder joints more than the blocky-shaped IMC reinforcements because of the strengthening effect from their sunflower petals, which primarily provide a tortuous path for 
deformation of the solder joints during creep. The $\mathrm{Cu}$-composite solder joints have scallop-shaped IMC morphology with a shape similar to a sunflower with thicker and shorter petals. Therefore, $\mathrm{Cu}$-composite solder joints also showed a lower steady-state creep rate than the Ni-composite solder joints with blocky IMC morphology. The Ni-composite solder joints with blocky IMC morphology did improve the steadystate creep behavior because of the thick IMC formed compared to the Ag-composite solder joints in which only a barely noticeable IMC layer was formed around each Ag particle. In general, to improve the creep resistance of the eutectic Sn-3.5Ag solder joint, the formation of a spatially extended IMC is the prerequisite. The morphology of the IMC determines the extent of improvement. The sunflower-shaped IMC morphology tends to render better mechanical properties to the solder joint as compared to the blocky-shaped morphology.

\section{SUMMARY AND CONCLUSIONS}

- The IMCs with different morphologies can be formed around reinforcing phases, depending on reinforcing particles and reflow conditions. Because the IMC formed around the Ni particle is sensitive to reflow profiles, it changes in shape from sunflower to blocky morphology with increasing time and temperature above liquidus.

- Maximum shear stress and the flow stress level of composite solder joints are strongly affected by testing temperature and simple shear rate.

- The Ni-composite solder joint containing sunflower IMC morphology exhibits the highest shear strength among the composite solder joints tested. The Ni-composite solder joint containing blocky IMC morphology exhibits much lower maximum shear stress than the Ni-composite solder joint containing sunflower IMC morphology at all test conditions.

- Grain-boundary deformation can be seen in the specimen deformed at $150^{\circ} \mathrm{C}$, while shear bands dominate deformation at $25^{\circ} \mathrm{C}$.

- The reinforcing phase in the composite solder joint may act as an obstacle to retard the propagation of deformation.

- The Ni-composite solder joint containing sunflower IMC morphology exhibits the best creep performance just as it behaves in the shear test.

\section{ACKNOWLEDGEMENTS}

The authors acknowledge the financial support for this work from the National Science Foundation under Grant No. NSF DMR-0081796. They also thank NSF for the RUI funding provided to support Dr. K.C. Chen's participation in the project. They also thank the Air Force Research Laboratory in providing partial funding for the acquisition of RSA-III.

\section{REFERENCES}

1. F. Guo, J. Lee, S. Choi, J.P. Lucas, T.R. Bieler, and K.N Subramanian, J. Electron. Mater. 30, 1073 (2001).

2. C.G. Kuo, S.M.L. Sastry, and K.L. Jerina, Microstructures and Mechanical Properties of Aging Materials, ed. P.K. Liaw, R. Viswanathan, K.L. Murty, E.P. Simonen, and D. Frear (Warrendale, PA: TMS, 1993), pp. 409-416.

3. J.W. Morris, Jr., J.L.F. Goldstein, and Z. Mei, JOM 45, 25 (1993).

4. A.W. Gibson, S. Choi, T.R. Bieler, and K.N. Subramanian, IEEE Int. Symp. Electron. Environment (Piscataway, NJ: IEEE, 1997), pp. 246-251.

5. A.W. Gibson, S. Choi, K.N. Subramanian, and T.R. Bieler, Reliability of Solders and Solder Joints, ed. P.K. Liaw, R. Viswanathan, K.L. Murty, E.P. Simonen, and D. Frear (Warrendale, PA: TMS, 1997), pp. 97-103.

6. F. Guo, S. Choi, J.P. Lucas, and K.N. Subramanian, J. Electron. Mater. 29, 1241 (2000).

7. S. Choi, J.G. Lee, F. Guo, T.R. Bieler, K.N. Subramanian, and J.P. Lucas, JOM 53, 22 (2001).

8. F. Guo, S. Choi, J.P. Lucas, and K.N. Subramanian, Solder. Surf. Mount Technol. 13, 7 (2001).

9. F. Guo, J. Lee, J.P. Lucas, K.N. Subramanian, and T.R. Bieler, J. Electron. Mater. 30, 1222 (2001).

10. J. Sigelko, S. Choi, K.N. Subramanian, and J.P. Lucas, J. Electron. Mater. 29, 1307 (2000).

11. J.G. Lee, K.C. Chen, and K.N. Subramanian, submitted to J. Electron. Mater.

12. H. Rhee, K.N. Subramanian, A. Lee, J.G. Lee, and T.R. Bieler, Solder. Surf. Mount Technol, in press.

13. P. Guerrazzi (B.S. thesis, Michigan State University, 1997).

14. J.P. Lucas, F. Guo, J. McDougall, T.R. Bieler, K.N. Subramanian, and J.K. Park, J. Electron. Mater. 28, 1270 (1999).

15. F. Guo, J.P. Lucas, and K.N. Subramanian, J. Mater. Sci.: Mater. Electron. 12, 27 (2001).

16. J. McDougall, S. Choi, T.R. Bieler, K.N. Subramanian, and J.P. Lucas, Mater. Sci. Eng. A285, 25 (2000).

17. J.G. Lee, F. Guo, K.N. Subramanian, and J.P. Lucas, Solder. Surf. Mount Technol. 14, 11 (2002).

18. J.H. Lau, ed., Thermal Stress and Strain in Microelectronics Packaging (New York: Van Nostrand Reinhold, 1993), pp. 472-479. 